\title{
PRESENCE OF SNP OF INTERLEUKIN17F IN PA- TIENTS WITH PERIODONTITIS IN A BULGARIAN POPULATION
}

\author{
Antoaneta Mlachkova, Zdravka Pashova-Tasseva, Hristina Popova, Maya Kicheva \\ Department of Periodontology, Faculty of Dental Medicine, Medical University \\ - Sofia, Bulgaria.
}

\begin{abstract}
Introduction: It's well known that the periodontitis is a complex disease initiated by bacteria, but modified by environmental factors and the host response. As any other chronic disease, the periodontal disease is influenced by the individual predisposition of the patient to develop the specific symptoms. The increasing number of studies in the area of the genetic factors and mechanisms of the patient to develop the specific condition is leading to the need for certain polymorphism's to be studied in details for the Bulgarian population.

Aim: The recent study aims to identify the presence of SNP of IL-17F in the Bulgarian population.

Materials and methods: In the study, 40 patients with periodontitis stage II, III and IV and 10 healthy control subjects were taking part. The age of the subjects varied between 23 and 75 with an average value of 46 years. Clinical and radiographic methods to establish the basic periodontal parameters were used. Laboratory methods were performed by means of Real-Time PCR for determination of SNP of Interleukin 17F (IL-17F) (-7488C/T rs_763780). The statistic data was processed with PCA - IBM SPSS Statistics Version 21. From all of the patients, informed consent was taken.

Results: The recent study collected information about the dominating genotype when studying SNP of IL$17 \mathrm{~F}$ for patients with periodontitis. The presence of two genotypes was established - genotype TT (92\%) and genotype CT $(8 \%)$. We have established specific tendencies about the distribution of major parameter for diagnosis of periodontitis such as BoP and BL/Age in both groups. The individual host susceptibility can be used as a diagnostic parameter leading to the development of screening methods in order suspectable individuals to be found.

Conclusion: The study has contributed to clarifying the genetic characteristic of the tested subject. The results confirmed the data from different studies that aim to research the genetic polymorphism of IL-17F in relation to periodontitis.
\end{abstract}

Keywords: periodontitis, gene polymorphism, SNP, Interleukin-17F,

\section{INTRODUCTION}

According to the Classification of Periodontal and Peri-Implant Diseases and Conditions 2017, the periodontitis is defined as "chronic multifactorial inflammatory disease associated with dysbiotic plaque biofilms and characterized by progressive destruction of the tooth-supporting apparatus" $[1,2]$. The loss of tooth supporting tissues manifests with clinical attachment loss and bone loss that is radiographically detected, periodontal pocket formation and gingival bleeding [2]. Although the role of the pathogenic microorganisms is unquestionable the recent understanding of the pathogenesis of the chronic inflammatory disease, in general, is referred in addition to the presence of specific genetic predisposition, in particular, the genetic polymorphisms. The topic of interest in the recent study is Interleukin -17 F (IL-17F).

The periodontal disease is initiated by elevated levels of specific highly virulent microbiota, but the further progression of the disease is modified by the individual, genetically determined host response to the bacterial challenge $[3,4,5]$. In the scientific literature, there are existing data about the personal genetic and systemic risk factors and environmental factors that are influencing the onset and the ongoing clinical condition (systemic diseases such as diabetes, osteoporosis, inflammatory bowel disease, smoking, stress, obesity). The pathogenetic mechanisms in periodontitis that are connected to the virulence of the bacteria are comparatively well known, and it is established that they can be controlled by means of the non surgical periodontal therapy. In present days there's growing interest and data about the presence of genetic determinants that are significant modifiers of the periodontal phenotype and individual 's host response to the conducted therapy.

Some genes and intergenetic interconnection are involved in the modification of the periodontal disease, and they can change the clinical appearance, the severity and the prognosis of the disease $[6,7,8,9]$.

The working hypothesis in the recent study is formed as a result of literature data investigation, and it is based on the suggestion that the presence of polymorphism of IL- 17F in $(-7488 \mathrm{C} / \mathrm{T})$ position could be related to the predisposition for the development of severe periodontitis. The identification of genetic factors that influence the initiation and progression of periodontitis would contrib- 
ute to the identification of risk individuals.

The scientific interest in IL-17 in the pathogenesis of periodontitis is important not only because of its specific role as inflammatory component leading to tissue destruction but also for its participation as a host defense mechanism against microbial invasion. Scientific data demonsrates that IL-17 can induce the production of antimicrobial antibodies which are defense reaction against the ongoing inflammatory and destructive processes in the periodontal tissues and also contributes to the inflammatory bone pathology in other diseases such as rheumatoid arthritis, inflammatory bowel disease and a number of autoimmune diseases [5, 10, 11, 12, 13, 14, 15].

Interleukin-17 is a proinflammatory cytokine that is secreted by activated T-cells. The Interleukin-17 family includes 6 members: IL-17A, IL-17B, IL-17C, IL-17D, IL17E (or IL-25) and IL-17F and five receptors: IL-17RARD and SEF. Th 17 cells are associated with a significant number of autoimmune diseases and are related to the development of severe inflammatory diseases. Cytokines related to Th17 cells, such as IL-17 and IL-22, are of major importance for the host's defense mechanisms against the activity of many extracellular pathogenic microorganisms $[17,18]$.

Many studies have demonstrated the presence of IL17 in periodontal tissues, gingival crevicular fluid and plasma of patients with periodontal disease [11, 19]. In order to establish whether IL-17A and IL-17F genetic polymorphisms are associated with periodontitis and for the immune-pathogenetic mechanisms to be cleared, there are investigations conducted which compare the presence of different allele mutations for IL-17A $197 \mathrm{~A} / \mathrm{G}$ (rs2275913) and IL- 17F-7488C/T (rs763780) and their significance for the development of periodontitis. The role of IL-17 is discussed in recent years because of the scientifically proved relation between that cytokine and the development of periodontitis. The facts are supported by animal and human studies. The dysregulation in its gene expression can promote not only the development of periodontitis but his increased susceptibility to Porphyromonas gingivalis (in an animal study) [19, 20, 21, 22]. The gene polymorphism of IL-23 (IL- 23R rs11209026) is also investigated in different populations suggesting a significant relation between IL-17 and IL-23 [20]. Many of the research have established the role of the increased levels of IL-17 and the increased production of RANK/ RANKL leading to increased synthesis of IL-23 - cascade that takes part in the osteoclastogenesis and the induction of bone resorption in periodontitis.

\section{AIM}

To establish the presence of gene polymorphism of IL-17F and to determine its influence on basic parameters of periodontitis.

\section{OBJECTIVES}

1. To determine the dominating genotype in the studied subjects.

2. To estimate significant interrelations between IL-
17F polymorphism and present periodontal status.

\section{MATERIALS AND METHODS}

In the recent study, 50 subjects were tested - 40 patients with diagnosis periodontitis and 10 patients with periodontal health. The age of the participants varies between 23 and 75 years, with an average value of 46 years. All of them were informed about the topics of the study, and have signed informed consent.

All of the participants with periodontitis were meeting the following criteria:

- Systemically healthy individuals with generalized periodontitis stage II-IV;

- Presence of periodontal pockets more than $5 \mathrm{~mm}$ at least at 10 teeth;

- Presence of periodontal pockets more than $7 \mathrm{~mm}$ at least at 4 teeth;

- CAL 5 and more than 5mm;

- Radiographically detected bone loss;

- Presence of at least 20 teeth;

- Patients who didn't have periodontal treatment for at least one year.

Criteria for exclusion from the study: patients with systemic diseases; patients with immunosuppressive therapy, pregnant and breastfeeding women.

Clinical methods for diagnostics were performed:

- Full Mouth Plaque Score (FMPS);

- Full Mouth Bleeding Score (FMBS);

- Bleeding on Probing (BOP);

- Probing Pocket Depth (PPD)*;

- Clinical Attachment Level (CAL)*.

The collected data were registered in a periodontal chart.

*The measurements were made in 6 sites for each tooth (mesiobuccal, buccal, distobuccal, mesiolingual, lingual, distolinqual), with graduated periodontal probe CP15 $\left(\right.$ Hu Friedy $\left.{ }^{\circledR}\right)$.

Radiographic methods of investigation were used in order to define diagnosis of periodontitis or periodontal health to the selected patients and the probands. Orthopantomography and retroalveolar periapical radiographs were used. In patients with periodontitis, parameters such as bone loss and the ratio BL/Age were measured.

Laboratory methods were performed by means of Real-Time PCR for determination of SNP of Interleukin 17F (IL-17F) (-7488C/T rs_763780). Epithelial cells from buccal mucosa is obtained by sterile tampon. Each tampon is incubated in buffer solution with Poteinkinase $\mathrm{K}$ at 55 degrees Celsius for 30 minutes with constant mixing. After removal of the tampon 400 microliters buffer solution optimized for DNA connection is added to each sample. The sample is centrifugated through column which is rinsed twice. DNA is eluted in 50 microliters buffer solution and is stored at -20 degree Celsius until the PCR analysis is performed. The PCR analysis is performed in 5 microliters genomic DNA with optimised sets of primers and two probes for genotype sampling:-7488C/T rs 763780. The real-time PCR is performed with 20 microlitres total volume, $1 \times 95 \mathrm{C} / 10 \mathrm{~min} ; 40 \times 95 \mathrm{C} / 15 \mathrm{sec}$. and 60C/1min. 
Statistical methods:

The statistic data was processed with PCA - IBM SPSS Statistics Version 21. For a level of significance, $\mathrm{p}<$ 0 . 05 was chosen. The following statistical methods were used:

1. Descriptive analysis

2. Pearson correlation analysis;

3. Variation analysis;

4. Student's T-test;

5. Nonparametric test of Man-Whitney.

\section{RESULTS}

1. Description of general data of all subjects in Table 1

The general data for the participants are presented

Table 1. Basic data of all participants

\begin{tabular}{|l|c|c|}
\hline \multirow{2}{*}{ Characteristic } & Meaning & $\begin{array}{c}\text { Relative } \\
\text { share }\end{array}$ \\
\hline Base (Count) & \multicolumn{2}{|c|}{$N=50$} \\
\hline \multirow{2}{*}{ Gender } & Male & $34 \%$ \\
\cline { 2 - 3 } & Female & $66 \%$ \\
\hline \multirow{2}{*}{ Smoker } & No & $66 \%$ \\
\cline { 2 - 3 } & Yes & $34 \%$ \\
\hline \multirow{2}{*}{ SNP for IL-17F rs_763780 } & TT & $92 \%$ \\
\cline { 2 - 3 } & CT & $8 \%$ \\
\hline \multirow{2}{*}{ Patient's status } & Periodontitis & $80 \%$ \\
\cline { 2 - 3 } & Healthy & $20 \%$ \\
\hline
\end{tabular}

The total number of participants (40 patients with periodontitis and 10 subjects with healthy periodontal structures) is $50-34 \%$ male and $66 \%$ female. The smokers are representing $66 \%$, nonsmokers $-34 \%$. From the tested subjects, $92 \%$ were positive for TT genotype of the tested SNP for IL-17F rs_763780, and 8\% were positive for CT genotype of SNP for IL-17F rs_763780.

\section{DATA WITH DISTRIBUTION OF THE TWO GENOTYPES, ISOLATED IN THE SNP FOR IL-17F RS_763780}

Fig. 1. Pie-chart with distribution genotype TT and genotype CT

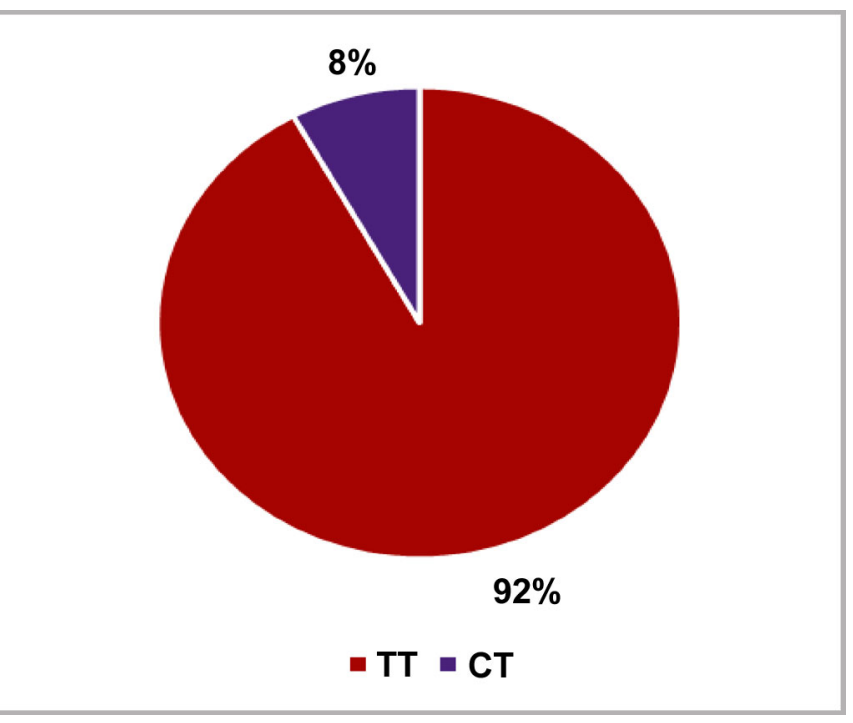

Pie-chart is demonstrating the distribution of the two genotypes isolated in the tested subjects. The dominating genotype in the studied population is TT. The majority of the patients are carriers of genotype TT ( $92 \%$ or 46 of all subjects), and only $8 \%$ (4 subjects) are carriers of CT genotype.

Only three are carriers of CT genotype from all of the periodontal patients, while only one of the probans has that genotype.Of the three periodontal patients, only one is male, and the other two are females. The healthy subject with CT genotype is female.

\section{DESCRIPTION OF SIGNIFICANT CORRELATIONS}

Table 2. Significant correlations between periodontal parameters in patients with the dominant genotype TT

\begin{tabular}{|c|c|c|c|c|c|c|c|c|c|c|c|c|c|}
\hline & & 蛋 & $\begin{array}{l}\widehat{a} \\
\infty \\
\sum_{4}^{\infty}\end{array}$ & $\begin{array}{l}\widehat{a} \\
\infty \\
\sum_{4}^{\infty}\end{array}$ & $\begin{array}{l}\stackrel{a}{a} \\
\stackrel{?}{+} \\
\stackrel{0}{a}\end{array}$ & 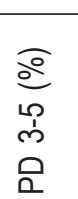 & $\begin{array}{l}\widehat{a} \\
\hat{a} \\
\dot{0} \\
\text { a }\end{array}$ & $\begin{array}{l}\widehat{a} \\
\hat{a} \\
\hat{a} \\
\hat{a}\end{array}$ & 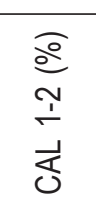 & 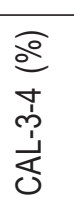 & $\begin{array}{l}\widehat{\varrho} \\
\frac{0}{0} \\
\frac{11}{\lambda} \\
\frac{\vec{d}}{0}\end{array}$ & $\begin{array}{l}\widehat{\varrho} \\
\text { o } \\
0\end{array}$ & 㟧 \\
\hline \multirow[t]{3}{*}{ Age } & $\begin{array}{l}\text { Pearson } \\
\text { Correlation }\end{array}$ & 1 & ,216 & ,283 &,$- 448^{* *}$ & ,202 & ,122 &,- 029 &,- 209 & ,211 & ,016 &, $332^{*}$ &,- 267 \\
\hline & Sig. (2-tailed) & & 149 & 057, & ,002 & 211 & ,470 & 865 & 213 & 209 & 926 & ,044 & 110 \\
\hline & $N$ & 46 & 46 & 46 & 46 & 40 & 37 & 37 & 37 & 37 & 37 & 37 & 37 \\
\hline \multirow[t]{3}{*}{ FMPS (\%) } & $\begin{array}{l}\text { Pearson } \\
\text { Correlation }\end{array}$ & ,216 & 1 &, $590^{* *}$ &,$- 478^{* *}$ &, $320^{*}$ &, $506^{* *}$ & , 178 &,$- 534^{* *}$ & , 150 &, $400^{*}$ &, $423^{* *}$ & ,000 \\
\hline & Sig. (2-tailed) & 149 & & 000, & ,001 & ,044 & ,001 & 291 & 001 & ,376 & ,014 & 009 & ,999 \\
\hline & $N$ & 46 & 46 & 46 & 46 & 40 & 37 & 37 & 37 & 37 & 37 & 37 & 37 \\
\hline
\end{tabular}




\begin{tabular}{|c|c|c|c|c|c|c|c|c|c|c|c|c|c|}
\hline \multirow[t]{3}{*}{ FMBS (\%) } & $\begin{array}{l}\text { Pearson } \\
\text { Correlation }\end{array}$ & , 283 &, $590^{* *}$ & 1 &,$- 312^{*}$ & ,203 & ,275 & ,062 &,- 145 & ,080 & ,088 &, $774^{* *}$ & ,072 \\
\hline & Sig. (2-tailed) & ,057 & , 000 & & ,035 & ,209 & , 099 & ,716 & ,393 & ,639 & ,603 & ,000 & ,673 \\
\hline & $N$ & 46 & 46 & 46 & 46 & 40 & 37 & 37 & 37 & 37 & 37 & 37 & 37 \\
\hline \multirow[t]{3}{*}{ PD 1-3 (\%) } & $\begin{array}{l}\text { Pearson } \\
\text { Correlation }\end{array}$ &,$- 448^{* *}$ &,$- 478^{* *}$ &,$- 312^{*}$ & 1 &,$- 815^{* *}$ &,$- 746^{* *}$ &,- 252 &, $514^{* *}$ &,- 285 &,- 256 &,$- 464^{* *}$ &,- 149 \\
\hline & Sig. (2-tailed) & ,002 & ,001 & ,035 & & ,000 & ,000 & 133 & ,001 & ,087 & 126 & ,004 & ,378 \\
\hline & $N$ & 46 & 46 & 46 & 46 & 40 & 37 & 37 & 37 & 37 & 37 & 37 & 37 \\
\hline \multirow[t]{3}{*}{ PD 3-5 (\%) } & $\begin{array}{l}\text { Pearson } \\
\text { Correlation }\end{array}$ & ,202 &, $320^{*}$ & ,203 &,$- 815^{* *}$ & 1 & ,257 &,- 291 &,- 252 & ,268 & ,000 &, $335^{*}$ & ,016 \\
\hline & Sig. (2-tailed) & 211 & ,044 & 209 & ,000 & & ,124 & ,081 & 133 & 109 & 999 & ,043 & ,925 \\
\hline & $N$ & 40 & 40 & 40 & 40 & 40 & 37 & 37 & 37 & 37 & 37 & 37 & 37 \\
\hline \multirow[t]{3}{*}{ PD 5-7 (\%) } & $\begin{array}{l}\text { Pearson } \\
\text { Correlation }\end{array}$ & ,122 &, $506^{* *}$ & ,275 &,$- 746^{* *}$ & ,257 & 1 & ,249 &,$- 482^{* *}$ & 183 &, $326^{*}$ &, $374^{*}$ & 207 \\
\hline & Sig. (2-tailed) & 470 & 001 & 099 &, 000 & ,124 & & ,137 & ,002 & ,277 & ,049 & 023 & ,218 \\
\hline & $N$ & 37 & 37 & 37 & 37 & 37 & 37 & 37 & 37 & 37 & 37 & 37 & 37 \\
\hline \multirow[t]{3}{*}{$\mathrm{PD}>7(\%)$} & $\begin{array}{l}\text { Pearson } \\
\text { Correlation }\end{array}$ &,- 029 & ,178 & ,062 &,- 252 &,- 291 & ,249 & 1 &,- 224 &,- 060 & ,287 & ,097 & 155 \\
\hline & Sig. (2-tailed) & ,865 & 291 & ,716 & 133 & 081 & 137 & & 182 & ,725 & 084 & ,569 & 360 \\
\hline & $N$ & 37 & 37 & 37 & 37 & 37 & 37 & 37 & 37 & 37 & 37 & 37 & 37 \\
\hline \multirow[t]{3}{*}{ CAL 1-2 (\%) } & $\begin{array}{l}\text { Pearson } \\
\text { Correlation }\end{array}$ &,- 209 &,$- 534^{* *}$ &,- 145 &, $514^{* *}$ &,- 252 &,$- 482^{* *}$ &,- 224 & 1 &,$- 477^{* *}$ &,$- 568^{* *}$ &,- 207 &,- 024 \\
\hline & Sig. (2-tailed) & ,213 & 001 & ,393 & ,001 & ,133 & ,002 & ,182 & & ,003 & ,000 & ,220 & 889 \\
\hline & $N$ & 37 & 37 & 37 & 37 & 37 & 37 & 37 & 37 & 37 & 37 & 37 & 37 \\
\hline \multirow[t]{3}{*}{ CAL-3-4 (\%) } & $\begin{array}{l}\text { Pearson } \\
\text { Correlation }\end{array}$ & ,211 & 150 & ,080 &,- 285 & ,268 & , 183 &,- 060 &,$- 477^{* *}$ & 1 &,$- 452^{* *}$ & 184 &,$- 367^{*}$ \\
\hline & Sig. (2-tailed) & ,209 & ,376 & ,639 & 087 & , 109 & ,277 & ,725 & ,003 & & ,005 & ,277 & 026 \\
\hline & $N$ & 37 & 37 & 37 & 37 & 37 & 37 & 37 & 37 & 37 & 37 & 37 & 37 \\
\hline \multirow[t]{3}{*}{$\begin{array}{l}\text { CAL } 5>1= \\
5(\%)\end{array}$} & $\begin{array}{l}\text { Pearson } \\
\text { Correlation }\end{array}$ & ,016 &, $400^{*}$ & ,088 &,- 256 & ,000 &, $326^{*}$ & ,287 &,$- 568^{* *}$ &,$- 452^{* *}$ & 1 & ,047 &, $370^{*}$ \\
\hline & Sig. (2-tailed) & ,926 & 014 & ,603 & ,126 & ,999 & ,049 & ,084 & ,000 & ,005 & & ,785 & ,024 \\
\hline & $N$ & 37 & 37 & 37 & 37 & 37 & 37 & 37 & 37 & 37 & 37 & 37 & 37 \\
\hline \multirow[t]{3}{*}{ BOP (\%) } & $\begin{array}{l}\text { Pearson } \\
\text { Correlation }\end{array}$ & ,332* &, $423^{* *}$ &, $774^{* *}$ &,$- 464^{* *}$ &, $335^{*}$ &, $374^{*}$ & ,097 &,- 207 & , 184 & ,047 & 1 & ,207 \\
\hline & Sig. (2-tailed) & 044 & 009 & 000 & ,004 & 043 & 023 &, 569 & ,220 & ,277 & ,785 & & ,218 \\
\hline & $N$ & 37 & 37 & 37 & 37 & 37 & 37 & 37 & 37 & 37 & 37 & 37 & 37 \\
\hline \multirow[t]{3}{*}{ BL/AGE } & $\begin{array}{l}\text { Pearson } \\
\text { Correlation }\end{array}$ &,- 267 & ,000 & ,072 &,- 149 & ,016 & ,207 & 155 &,- 024 &,$- 367^{*}$ &, $370^{*}$ & ,207 & 1 \\
\hline & Sig. (2-tailed) & 110 & ,999 & ,673 & ,378 & ,925 & ,218 & ,360 & 889 & ,026 & ,024 & ,218 & \\
\hline & $N$ & 37 & 37 & 37 & 37 & 37 & 37 & 37 & 37 & 37 & 37 & 37 & 37 \\
\hline
\end{tabular}

In patients with the dominant genotype TT, are established a significant correlation between the following parameters, which indicate the existence of an objective connection:

1. A significant positive correlation between age and $\mathbf{B o P} *$-with increasing age increased the places with bleeding from the bottom of the periodontal pockets;

2. A significant positive correlation was found be- tween FMPS and FMBS * * - the present of more plaque leads to a greater prevalence of superficial bleeding; FMPS and PD 3-5* and PD 5-7**-plaque is located in large quantities in moderate and deep pockets. FMPS and CAL5 e" 5 *-the presence of plaque leads to patients to a greater loss of attachment; FMPS and BoP $* *$ - the present of many places with plaque, bleeding from the bottom of the pockets is more expressed; 
3. A significant negative correlation between FMBS and PD 1-3* - an absence of bleeding in shallow pockets;

4. A significant negative correlation between PD 13 and PD 3-5** and PD 5-7**- in the presence of shallow pockets, the deepest periodontal sites are less; between PD 1-3 and BOP**- in shallow periodontal pockets, there is an absence of Bleeding on Probing;

5. A significant positive correlation between PD 57 and CAL $\geq \mathbf{5 m m} *$ - in the presence of deep periodontal pockets there's a prevalence of the clinical attachment loss; between PD 5-7 mm and BOP- with an increase of the number of deep periodontal sites the Bleeding of Probing is greater; between PD 5-7 $\mathrm{mm}$ and FMPS- the presence of deep periodontal pockets correlates with the presence of more dental plaque;

6. A significant positive correlation between CAL 3$4 \mathrm{~mm}$ and CAL $\geq 5 \mathrm{~mm}$ and BL/Age*- the clinical attachment loss increases significantly with the increase of the ratio $\mathrm{Bl} /$ Age.

\section{DESCRIPTION OF STATISTICALLY SIGNIFI- CANT INTERRELATIONS}

Table 3. Hypothesis checking for statistically significant differences between the average values of the parameters of the subjects with TT and CT genotype:

\begin{tabular}{|c|c|c|c|}
\hline \multirow{2}{*}{$\begin{array}{c}\text { Tested } \\
\text { parameter }\end{array}$} & \multicolumn{2}{|c|}{ TT } & \multirow{2}{*}{$\begin{array}{c}\text { P- } \\
\text { value }\end{array}$} \\
\cline { 2 - 3 } Average & Average & 0,583 \\
\hline Age & 45,63 & 49,25 & 0,83 \\
\hline FMBS (\%) & 82,25 & 84,38 & 0,746 \\
\hline PD 1-3 (\%) & 69,53 & 74,15 & 0,181 \\
\hline PD 3-5 (\%) & 52,59 & 72,55 & 0,155 \\
\hline PD 5-7 (\%) & 34,67 & 20,57 & 0,408 \\
\hline PD > 7 (\%) & 5,95 & 10,97 & 0,384 \\
\hline CAL 1-2 (\%) & 35,46 & 28,87 & 0,551 \\
\hline CAL-3-4 (\%) & 42,66 & 45,27 & 0,791 \\
\hline CAL 5 \& > 5 (\%) & 21,8 & 25,87 & 0,709 \\
\hline BOP (\%) & 79,17 & 75,47 & 0,775 \\
\hline BL/AGE & 1,07 & 0,59 & 0,079 \\
\hline
\end{tabular}

The data showed no statistically significant differences between the clinical and paraclinical parameters in both groups by level of significance $\mathrm{p}<0.05$.

5. DESCRIPTION OF DETAILED INFORMATION ABOUT THE TWO DIFFERENT GENOTYPES AND BASIC PARAMETERS IN THE DIAGNOSIS OF PERIODONTITIS.
Graphic 1. Box-plot analysis representing PD 5-7 $(\%), \mathrm{PD}>7(\%), \mathrm{CAL}-3-4(\%), \mathrm{CAL} \geq 5(\%)$ and $\mathrm{BOP}(\%)$ for genotype $\mathrm{TT}$

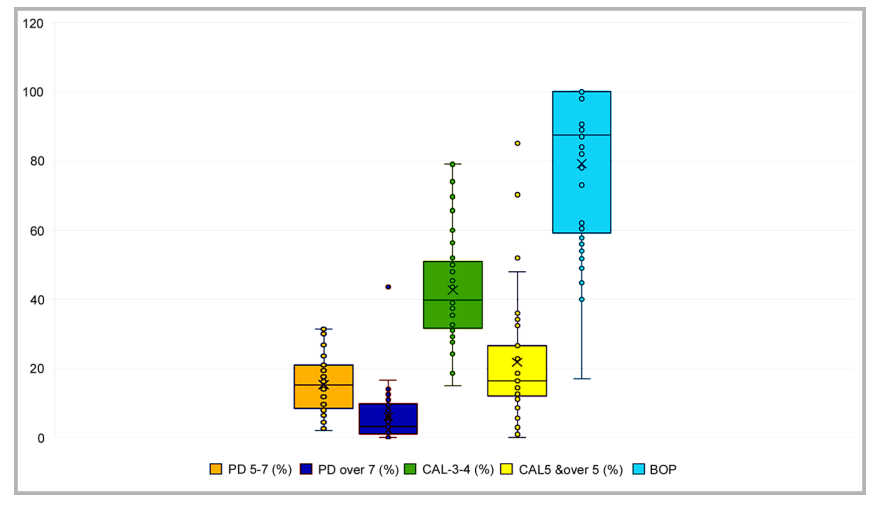

The data from the box- plot are representing the distribution of PD 5-7mm, PD > 7mm, CAL 3-4mm, CAL e" $5 \mathrm{~mm}$ and BoP in genotype TT individuals:

- $\quad$ PD 5-7 mm are just over 20\%;

- $\quad$ PD $>7 \mathrm{~mm}$ is almost $10 \%$;

- $\quad$ CAL 3-4mm are just over 50\%;

- $\quad$ The sites with CAL $\geq 5 \mathrm{~mm}$ are almost $30 \%$;

- $\quad$ BoP varies between 80 \& 100\%.

Based on the results, we can conclude that in a patient with periodontitis and isolated genotype TT, the percentage of the periodontal pockets with depth $5-7 \mathrm{~mm}$ is twice as high as the percentage of the pockets with depth over $7 \mathrm{~mm}$. In the same group, the periodontal sites with clinical attachment loss 3-4 $\mathrm{mm}$ dominate the sites with $\mathrm{CAL} \geq 5 \mathrm{~mm}$. The box-plot analysis demonstrates the presence of a significant percentage of sites with severe periodontal destruction with a distribution of bleeding on probing up to $100 \%$.

Graphic 2. Box-plot analysis PD 5-7 (\%), PD > 7 (\%), CAL-3-4 (\%), CAL $\geq 5(\%)$ and BOP (\%) for genotype $\mathrm{CT}$

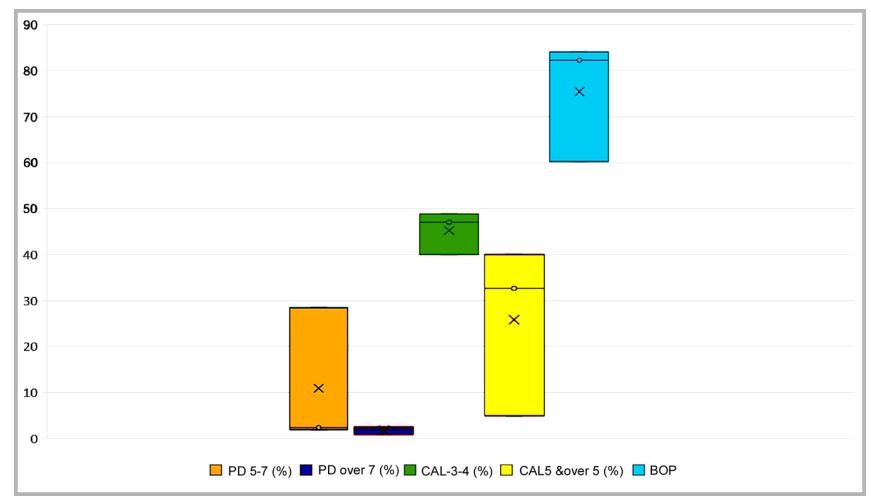

The graphic is showing the distribution of basic periodontal parameters in patients with genotype CT:

\footnotetext{
- $\quad$ PD $5-7 \mathrm{~mm}$ is near $30 \%$;

- $\quad$ PD $>7$ are almost $2 \%$;

- CAL 3-4mm are almost 50\%.

- $\quad$ CAL $\geq 5$ are $40 \%$;

- $\quad$ BoP is more than $80 \%$.
} 
Based on the result, we established a significant prevalence of periodontal pockets with a depth between 5 and $7 \mathrm{~mm}$; the percentage of the periodontal pockets with depth more than $7 \mathrm{~mm}$ is significantly lower. Half of the periodontal sites are characterized by moderate values of clinical attachment loss; The percentage of the most severely destructed sites is comparatively low. The bleeding on probing is more than $80 \%$.

Graphic 3. Box- plot with data for PD 5-7 (\%) and genotype $\mathrm{CT}$ and TT

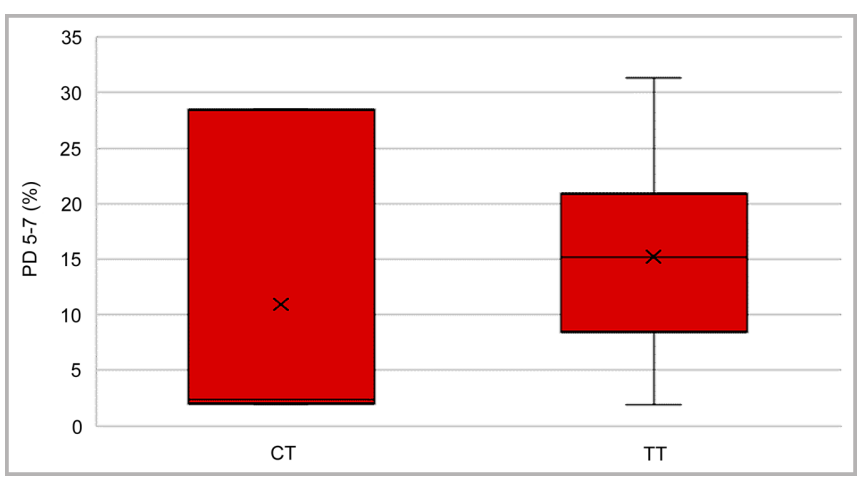

Graphic 4. Box - plot with data for PD > $7(\%)$ and genotype

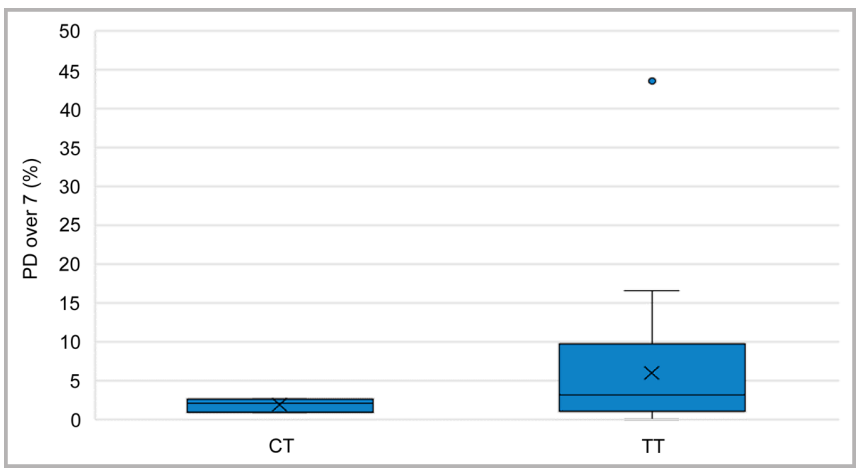

The data from both box-plot graphics are showing that in TT genotype periodontal patients, the periodontal sites with depth $5-7 \mathrm{~mm}$ are $\mathbf{1 8 \%}$ more than the sites in patients with CT genotype (PD 5-7mm just as $20 \%$ in Genotype TT vs $2 \%$ in Genotype CT). The sites with PD more than $7 \mathrm{~mm}$ in patients with genotype TT are around $\mathbf{8 \%}$ more than the deepest periodontal sites in patients with CT genotype (10\% in genotype TT vs $2-3 \%$ in genotype CT).
Graphic 5. Box-plot with data for CAL-3-4(\%) by genotype CT and TT

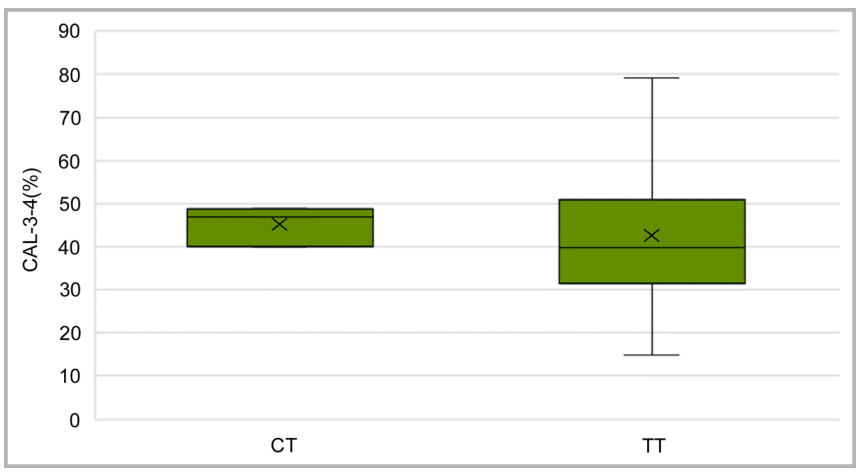

Graphic 6. Box- plot with data for $\mathrm{CAL} \geq 5(\%)$ by genotype CT and TT

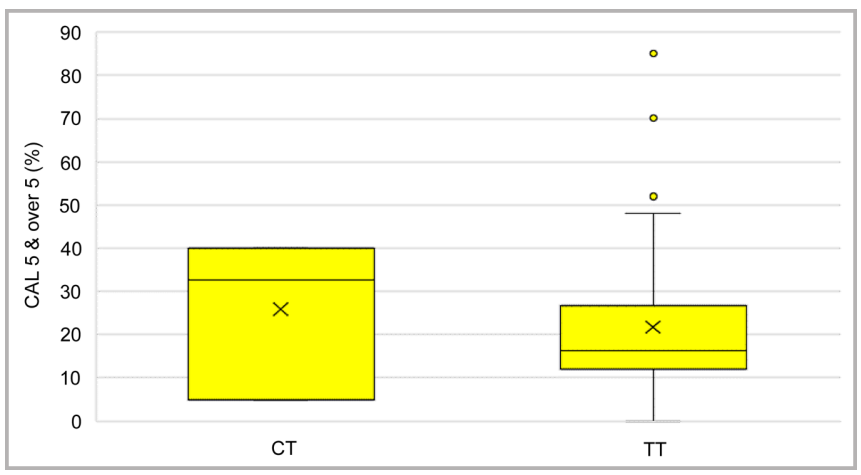

The results from the box-plot graphics are showing that both genotypes have a similar percentage of moderate clinical attachment loss (CAL 3-4mm 50\%). In contrast, the percentage of periodontal sites with severe attachment loss are demonstrating higher values in CT genotype patients compared ith TT genotype patients (CAL $\geq \mathbf{5 m m}$ $28 \%$ in genotype TT vs $\mathbf{4 0 \%}$ in genotype $\mathrm{CT}$ ).

Graphic 7. Box-plot is presenting BOP (\%) by genotype CT and TT.

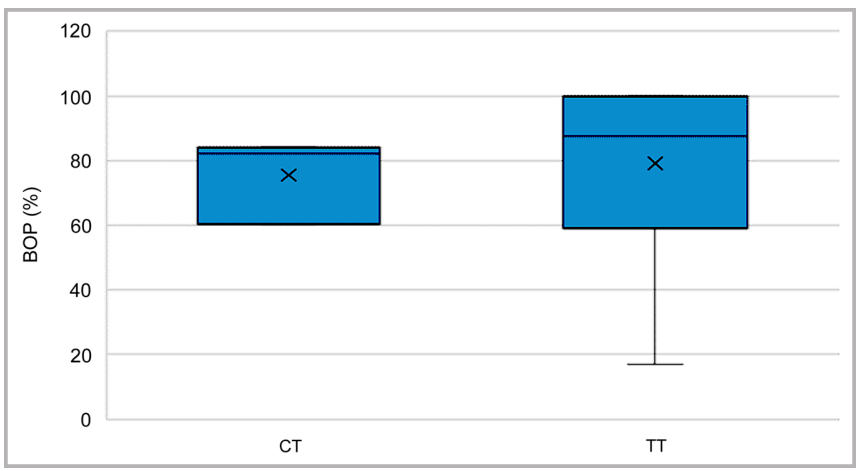

The box-plot graphic is presenting the high percentage of Bleeding on Probing among both genotype patients - BoP $100 \%$ in genotype TT vs just as $80 \%$ in genotype CT. 
Graphic 8. Box- plot with data BL/AGE by genotype CT and TT.

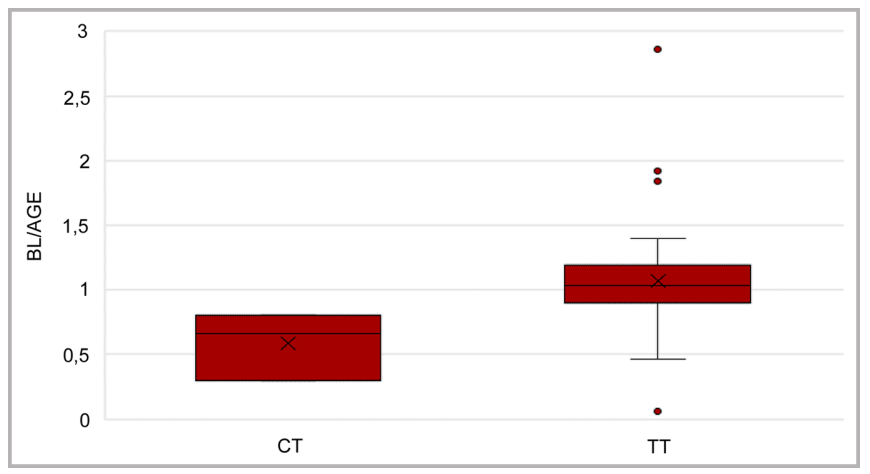

The graphic is representing the ratio BL/Age in both genotype patients, which shows a higher value in patients with genotype TT compared to genotype CT $(1,2$ in genotype TT vs 0,8 in genotype CT).

\section{DISCUSSION}

The recent study achieved information about the dominating genotype in 50 test subjects in the Bulgarian population. First of all, we established significant domination of TT genotype - 92\%- of the participants were positive on TT genotype of SNP for IL-17F rs_763780.

When comparing the estimated basic periodontal parameters in both genotype subjects - genotype TT and genotype CT, we made the following conclusions:

- Prevalence of periodontal pockets with depth 5$7 \mathbf{m m}$ in both genotype groups. It seems that pockets with depth 5-7 $\mathrm{mm}$ are dominating in both groups;

- A lower percentage of the deepest periodontal sites ( $\mathbf{P D}>\mathbf{7} \mathbf{m m}$ ), but still with higher value in patients with TT genotype compared with patients with CT genotype (10\% for TT genotype vs $\mathbf{2 \%}$ for CT genotype);

- In both genotype patients, the dominating values of CAL are between 3-4mm (CAL 3-4 mm 50\%) with minimal prevalence for the group with genotype CT (40\% for genotype CT vs $\mathbf{3 0 \%}$ for genotype TT);

- The clinical parameter Bleeding on probing demonstrates extremely high levels - more than $80 \%$ (up to $\mathbf{1 0 0 \%}$ for genotype TT and just over $\mathbf{8 0 \%}$ for genotype CT);
- A higher value of the parameter BL/Age in patients with genotype TT compared with patients with genotype CT (1, 2 in genotype TT vs 0,8 in genotype CT).

We have established a tendency for a higher value of $\mathrm{BoP}$ and $\mathrm{Bl} / \mathrm{Age}$ in patients with genotype TT. The tested parameters, despite the differences, have shown no statistical significance.

The distribution of the investigated polymorphism was $100 \%$ - all of the tested subjects were positive for this SNP of IL-17F rs_763780 with significant prevalence of the TT genotype compared to the CT genftype. Despite these findings no significance appear to be present in relation with the parameters of the periodontitis. This could be explained with the small number of the participants. Our results are supported by data from a Brasilian and Malaysian population - IL-17F polymorphism was not associated with periodontal disease. The lack of association of this genetic polymorphism with periodontal disease was found also in a Polish population $[18,23]$. The absence of significant correlations between SNP of IL-17F and periodontitis leads to the conclusion that yet this polymorphism cannot be included as a predictor for suspectability and development of periodontitis and still is not reliable diagnostic and screening marker.

The study has contributed to clarifying the genetic characteristic of the tested subject. The results confirmed the data from different studies that aim to research the genetic polymorphism of IL-17F in relation to periodontitis. Further additional studies in larger popultions are required in order to clarify the potential role of this genetic polymorphism in the pathogenesis of periodontitis.

\section{CONCLUSION}

1. There's a significant dominance of TT genotype for SNP for IL-17F rs_763780 in Bulgarian population.

2. The patients with both genotypes were showing the dominance of periodontal pockets with depth 5-7 mm;

3. The parameter BoP and the ratio BL/Age is higher in patients with genotype TT.

The recent research is the result of a study under Grant project, financed by the Council of Medical Science under MU - Sofia.

\section{REFERENCES:}

1. Papapanou PN, Sanz M, Buduneli N, Dietrich T, Feres M, Fine DH, et al. Periodontitis: Consensus report of workgroup 2 of the 2017 World Workshop on the Classification of Periodontal and Peri-Implant Diseases and Conditions. J Periodontol. 2018 Jun;89 Suppl 1:S173-S182. [PubMed] [Crossref]

2. Tonetti MS, Greenwell H, Kornman KS. Staging and grading of periodontitis: Framework and proposal of a new classification and case definition. J Periodontol. 2018 Jun;89 Suppl 1:S159-S172. [PubMed] [Crossref]

3. Hart TC, Kornman KS. Genetic factors in the pathogenesis of periodontitis. Periodontol 2000. 1997 Jun;14:202-15. [PubMed]

4. Laine ML, Crielaard W, Loos BG. Genetic susceptibility to periodontitis.
Periodontol 2000. 2012 Feb;58(1):3768. [PubMed]

5. TBlvan T, Mohor C, Chisnoiu D, Cristea V, Свmpian S. Expression of Interleukin (IL)-1 в, IL-8, IL-10 and IL13 in chronic adult periodontitis progression. Arch Med. 2017; 9:3-11.

6. Larsson L, Thorbert-Mros S, Rymo L, Berglundh T. Interleukin-10 Genotypes of the -1087 Single Nucleotide Polymorphism Influence Sp1 Ex- 
pression in Periodontitis Lesions. $J$ Periodontol. 2011 Sep;82(9):1376-82. [PubMed] [Crossref]

7. Nicu EA, Loos BG. Polymorphonuclear neutrophils in periodontitis and their possible modulation as a therapeutic approach. Periodontol 2000. 2016 Jun;71(1):140-63. [PubMed]

8. Persson GR. Dental geriatrics and periodontitis. Periodontol 2000. 2017 Jun;74(1):102-115. [PubMed]

9. Taylor JJ, Preshaw PM, Donaldson PT. Cytokine gene polymorphism and immunoregulation in periodontal disease. Periodontol 2000. 2004; 35:158-82. [PubMed]

10. Dosseva-Panova V. [Bacterial findings and inflammatory components of the host response in severe chronic periodontitis.] [dissertation]. Sofia: Medical University- Sofia; 2018. 217 p. [in Bulgarian]

11. Mlachkova A, Popova Hr, Kicheva M. Severity of chronic periodontitis in relation with IL-1B gene polymorphism. Problems of Dental Medicine. 2011; 37(1):6-14

12. Chen X, Huang J, Zhong L, Ding C. Quantitative assessment of the associations between interleukin- 8 polymorphisms and periodontitis sus- ceptibility. J Periodontol. 2015 Feb;86(2):292-300. [PubMed]

13. Chen D, Zhang T-L, Wang X. Association between Polymorphisms in Interleukins 4 and 13 Genes and Chronic Periodontitis in a Han Chinese Population. Biomed Res Int. 2016; 2016:8389020. [PubMed] [Crossref]

14. Popova Chr, Dosseva-Panova V, Mlachkova A. Correlation of gene expression of main inflammatory cytokines and the severity of chronic periodontitis. J of IMAB. 2014 Jul-Sep;20(3): 563-566. [Crossref]

15. Schaefer AS. Genetics of periodontitis: Discovery, biology, and clinical impact. Periodontol 2000. 2018 Oct;78(1):162-173. [PubMed] [Crossref]

16. Lester SR, Bain JL, Johnson RB, Serio FG. Gingival concentrations of interleukin-23 and -17 at healthy sites and at sites of clinical attachment loss. J Periodontol. 2007 Aug;78(8):1545-50. [PubMed]

17. Yoshie H, Kobayashi T, Tai H, Galicia JC. The role of genetic polymorphisms in periodontitis. Periodontol 2000. 2007; 43:102-32. [PubMed]

18. Zacarias JM, Sippert EA, Tsuneto PY, Visentainer JE, de Oliveira e Silva C, Sell AM. The Influence of Interleukin 17A and IL17F Polymorphisms on Chronic Periodontitis Disease in Brazilian Patients. Mediators Inflamm. 2015;2015:147056. [PubMed] [Crossref]

19. Zhang J, Sun X, Xiao L, Xie C, Xuan D, Luo G. Gene polymorphisms and periodontitis. Periodontol 2000. 2011 Jun;56(1):102-24. [PubMed]

20. Erdemir E, Hendek K, Kocakap B, Ozkan Y. Interleukin (IL)-17F and IL23-R gene polymorphisms in Turkish population with periodontitis. $J$ Res Med Den Sci. 2015 Apr-Jun;3(2):104-8.

21. Laine ML, Loos BG, Crielaard W. Gene polymorphisms in chronic periodontitis. Int J Dent. 2010;2010:324719.

[PubMed]

22. Silva N, Abusleme L, Bravo D, Dutzan N, Garcia-Sesnich J, Vernal R, et al. Host response mechanisms in periodontal diseases. J Appl Oral Sci. 2015 May-Jun;23(3):329-55. [Crossref]

23. Mazurek-Mochol M, Kozak M, Malinowski D, Safranow K, Pawlik A. IL-17F Gene rs763780 and IL-17A rs2275913 Polymorphismsin Patients with Periodontitis. Int. J. Environ. Res. Public Health. 2021, 18(3):1081. [Crossref]

Please cite this article as: Mlachkova A, Pashova-Tasseva Z, Popova H, Kicheva M. Presence of SNP of Interleukin17F in patients with periodontitis in a Bulgarian population. J of IMAB. 2021 Apr-Jun;27(2):3692-3699.

DOI: https://doi.org/10.5272/jimab.2021272.3692

Received: 13/04/2020; Published online: 07/04/2021

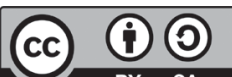

Address for correspondence:

Zdavka Pashova-Tasseva

Department of Periodontology, Faculty of Dental Medicine, Medical University - Sofia,

1 George Sofiiski str., 1431 Sofia, Bulgaria.

E-mail: z.pashova@abv.bg 